\title{
KENYAMANAN GERAK DAN VISUAL PENGUNJUNG DI RUANG TUNGGU ICU RUMAH SAKIT KLUNGKUNG
}

\author{
I Made Juniastra \\ Program Study Teknik Industri, Fakultas Teknik, Universitas Mahendradatta \\ JI. Ken Arok No. 12 Peguyangan, Denpasar, Bali 80115 \\ Email : juniastra@gmail.com
}

\begin{abstract}
Abstrak - Ruang tunggu adalah tempat dimana para pelaku aktivitas dengan berbagai kondisi fisik dan mental yang beragam berkumpul dalam satu ruangan. Tekanan psikis dengan beban pikiran terhadap pasien yang umumnya adalah orang /kerabat dekat menyebabkan kondisi fisik ikut menurun. Oleh karena itu kesehatan ruang tunggu ini mutlak harus terjaga agar bisa menunjang kesehatan penunggu pasien agar tetap sehat dan higienis selama menunggu pasien. Rumah Sakit Umum Klungkung adalah rumah sakit terbesar di wilayah Bali timur. Pelayanannya mencakup wilayah Klungkung, Karangasem dan juga Bangli. Penelitian ini diarahkan untuk mengkaji kenyamanan gerak dan visual penunggu pasien di ruang ICU dari segi arsitektur dan pencahayaannya dalam mendukung kesehatan pengguna dan mengkomparasi dengan gambar serta literatur terkait. Tujuan penelitian ini adalah untuk mengevaluasi kenyamanan gerak dan visual bangunan dengan standar-standar terkait untuk menunjang kesehatan pengguna.
\end{abstract}

Kata kunci : Kenyamanan Gerak Dan Visual; Ruang Tunggu ICU; Rumah Sakit Klungkung

\begin{abstract}
Abtract - The waiting room is a place where activity actors with various physical and mental conditions gather in one room. The psychological pressure with the burden of thoughts on patients, who are generally close relatives, causes their physical condition to decline. Therefore, the health of this waiting room absolutely must be maintained in order to support the health of the patient in order to stay healthy and hygienic while waiting for the patient. Klungkung General Hospital is the largest hospital in the eastern Bali region. Its services cover the Klungkung, Karangasem and Bangli areas. This study was aimed at assessing the comfort of movement and visuals of patient waiters in the ICU in terms of architecture and lighting in supporting user health and comparing with pictures and related literature. The purpose of this study was to evaluate the motion and visual comfort of the building with related standards to support user health.
\end{abstract}

Keywords: Motion and Visual Comfort; ICU Waiting Room; Klungkung Hospital

\section{PENDAHULUAN}

Ruang ICU dapat diartikan sebagai ruangan di rumah sakit yang digunakan untuk perawatan intensif bagi pasien dengan kondisi yang sudah gawat. ICU sendiri adalah singkatan dari Intensive Care Unit. Ruangan ini dilengkapi dengan peralatan-peralatan khusus yang tidak terdapat di kamar perawatan biasa. Alat-alat tersebutlah yang digunakan untuk menunjang fungsi organ yang rusak pada pasien, agar bisa bertahan hidup.Aturan yang berlaku di ruang ICU pun berbeda dari kamar rumah sakit biasa. Misalnya saja, keluarga atau orang lain tidak bisa dengan mudah masuk menjenguk pasien yang sedang dirawat di dalamnya.

Di ruang ICU, pasien-pasien dengan kondisi di atas akan dirawat oleh tim yang terdiri dari dokter, perawat, dan dokter spesialis yang memang terlatih khusus untuk menghadapi situasi kritis.Satu orang perawat biasanya bertugas untuk merawat maksimal dua pasien. Kondisi ini berbeda dari layanan rawat inap biasa di rumah sakit, yang memungkinkan seorang perawat merawat lebih dari dua pasien. Selain itu, pasien juga akan dipasangi berbagai peralatan penunjang agar organ vital 
di tubuh masih tetap bisa bekerja.

\section{METODE PENELITIAN}

Metode pertama adalah dengan observasi langsung dengan datang dan melihat sebagai melihat, mengamati, mendengarkan, dan memperhatikan secara langsung, kemudian hasil pengamatan direkam dalam bentuk catatan atau dengan alat bantu lainnya.

Metode kedua adalah study gambar objek penelitian. Study gambar perencanaan sangat diperlukan agar bisa dipahami luasan ruang pelayanan dan juga area tunggu. Karena gambar rencana ini adalah dimensi real dari objek penelitian.

\section{TINJAUAN PUSTAKA}

\section{Ruang Tunggu}

Menurut Kamus Besar Bahasa Indonesia (KBBI), pengertian ruang tunggu adalah ruang atau tempat yang diperuntukan untuk menunggu atau ruang yang disediakan khusus bagi pengunjung untuk menunggu. Ruangan ini utamanya terdiri dari jajaran kursi yang ditata rapi disesuaikan dengan kapasitas pengunjung. Selain itu, ruang tunggu juga dilengkapi dengan beberapa fasilitas pendukung dengan penataan yang sedemikian rupa guna memberikan kenyamanan bagi pengguna ruang tersebut. Ruang tunggu di rumah sakit salah satunya ada di ICU untuk menunggu pasien dalam perawatan khusus yang menyangkut kegawat daruratan. Perawatan di ruang ICU bisa berlangsung selama beberapa hari atau bahkan hingga tahunan. Semua itu tergantung dari kondisi pasien. Saat mulai pulih, pasien bisa dipindahkan ke ruang rawat inap biasa selama beberapa waktu sebelum akhirnya diperbolehkan untuk pulang.

\section{Elemen Perencanaan Ruang Tunggu Rumah Sakit}

Bagi pihak rumah sakit, hal yang harus dipenuhi tidak hanya memastikan rumah sakit memiliki ruang tunggu saja. Menurut aturan Kementerian Kesehatan RI, ada beberapa persyaratan ruang tunggu rumah sakit yang harus dipenuhi, seperti:

- Ruang tunggu harus tersedia dengan kapasitas memadai;

- Luas ruang tunggu sesuai dengan kapasitas pelayanan (perhitungan: 1-1,5 m2 per orang);

- Pertukaran udara alami atau mekanik dalam ruangan harus baik;

- Total pertukaran udara sedikitnya 6 kali per jam;

- Ruang tunggu harus terkena pencahayaan alami; Penataan jalur sirkulasi bagi pengunjung/pasien yang jelas untuk menuju ke front desk, lift, dan fasilitas rawat jalan lainya. Apabila memungkinkan dibuat jalur pasien infeksi dan pasien noninfeksi yang terpisah untuk mengurangi resiko penularan penyakit;

- Adanya fungsi tambahan yang mendukung kegiatan pengunjung di ruang tunggu, yaitu toilet, tempat penitipan barang, operator telepon, telepon umum, serta meja perawat yang dapat dihubungkan dengan ruangan lain.

- Harus menyediakan alat atau fasilitas disinfektan tangan.

Selain beberapa syarat di atas, ruang tunggu rumah sakit untuk pasien tidak menular dengan pasien menular harus dipisah. Utamanya, bagi pasien anak-anak dan juga kebidanan harus memiliki ruang tunggu khusus yang steril.Ruang tunggu rumah sakit juga harus tersedia di setiap bagian yang berbeda-beda. Tak hanya untuk poli pemeriksaan saja, tapi juga ruangan lain seperti radiodiagnostik, rehabilitasi medik, atau ruang penerimaan di bagian depan rumah sakit.Kapasitas dan luas ruang tunggu rumah sakit harus memadai sesuai dengan kebutuhan pelayanan. Jangan sampai ruang tunggu tidak bisa menampung jumlah pasien sehingga pasien harus menunggu di area yang tidak seharusnya.

\section{Aturan menjenguk pasien di ruang ICU}

Karena pasien yang dirawat di ICU kondisinya rentan, maka tidak sembarang orang bisa menjenguk. Biasanya, kunjungan dibatasi hanya untuk keluarga kandung. Selain itu, ada 
beberapa aturan yang umumnya diberlakukan di ruang ICU, seperti: Harus mencuci tangan sebelum dan sesudah masuk ruang ICU untuk mencegah penyebaran infeksi; Dilarang menyalakan telepon genggam karena bisa mengganggu kerja alat penunjang medis; Dilarang membawa barang saat menjenguk, seperti bunga atau boneka. Beberapa barang masih bisa dibawa, tapi sebelumnya harus konfirmasi dengan petugas jaga ICU. Pada beberapa kondisi, orang yang menjenguk masih boleh menyentuh pasien sambil mengajaknya bicara. Untuk pasien-pasien tertentu, mendengar suara orang terdekatnya bisa membantu di masa pemulihan.

\section{Syarat-syarat Ruang Tunggu Rumah Sakit}

Menurut Neufert (2000), syarat-syarat ruang tunggu rumah sakit antara lain sebagai berikut:

- Meja sebagai tempat informasi, administrasi, dan kasir dengan ukuran panjang $180 \mathrm{~cm}$ dan tinggi maksimal 120 $\mathrm{cm}$ untuk orang normal, sedangkan tinggi maksimal untuk penyandang disabilitas adalah $86 \mathrm{~cm}$.
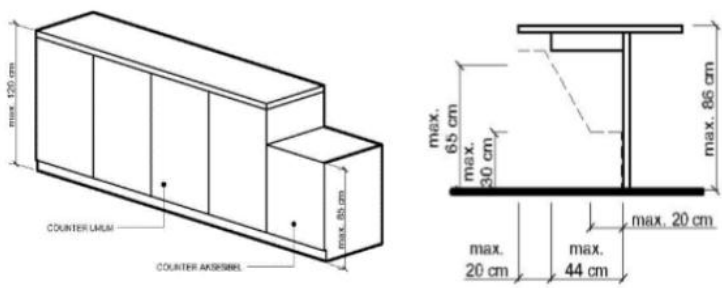

Gambar 1. Standar ukuran meja counter (Sumber: Neufert P., 2019)

- Area antri yang harus disediakan dengan kapasitas yang cukup di depan front desk sebagai tempat antri berdiri bagi pengunjung. Namun saat ini sudah banyak rumah sakit yang meminimalisir jumlah antrian berdiri karena mengingat sebagian besar pengunjung adalah pasien dengan kondisi fisik yang lemah. Sebagai penggantinya rumah sakit menyediakan nomor antrian. Meskipun begitu ruang antri harus tetap disediakan, hanya saja dengan dimensi yang tidak terlalu luas.

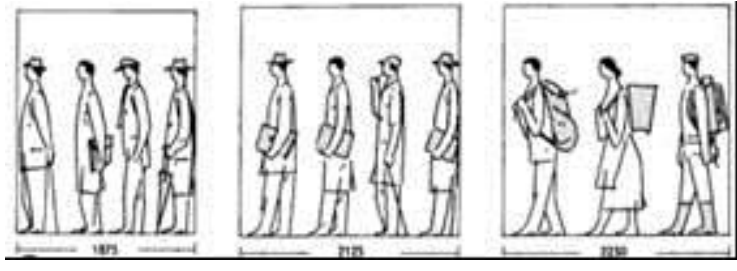

Gambar 2. Standar ukuran untuk antrian

(Sumber: Neufert P., 2019)

- Tempat penyimpanan barang. Agar terlihat rapi dan tidak berantakan, rumah sakit perlu menyediakan area locker untuk menyimpan data-data atau rekam medik pasien. Sebaiknya locker penyimpanan diletakkan berdekatan dengan petugas pendaftaran.

- Telepon umum merupakan alat komunikasi yang sangat penting dan harus disediakan rumah sakit yang diletakkan berdekatan dengan admin atau operator yang dekat dengan front desk.

- Papan informasi atau papan petunjuk arah yang diletakkan di tempat strategis untuk memudahkan pengunjung mencari area Instalasi Rawat Jalan yang dituju. Sebaiknya papan petunjuk arah diletakkan dekat dengan pintu masuk.

- Perabot. Image ruang tunggu sebuah Instalasi Rawat Jalan pada rumah sakit dapat dibentuk melalui pemilihan dan tata letak perabot berdasarkan fungsi ruangnya.

\section{Standar Ukuran Peralatan Medis di Ruang Tunggu Rumah Sakit}

- Kereta dorong pasien (stretcher), berperan penting sebagai alat bantu gerak bagi pasien yang berfungsi membantu mempermudah ruang gerak pasien untuk berpindah dari satu tempat ke tempat lain dengan bantuan orang lain untuk mendorong.

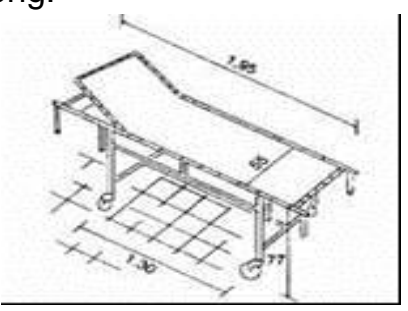

Gambar 4. Standar ukuran kereta dorong

(Sumber: Neufert P., 2019) 
- Lorong adalah jalan kecil atau jalan sempit yang menghubungkan antar gedung atau ruang satu dengan ruang lainnya. Lorong atau disebut juga dengan koridor hanya dikhususkan untuk pejalan kaki.

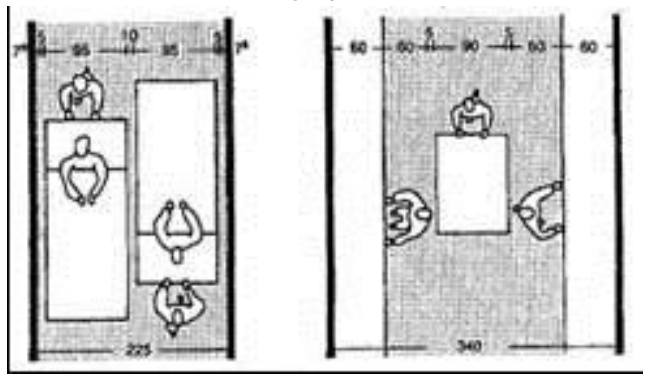

Gambar 5. Standar ukuran lorong rumah sakit. (Sumber: Neufert, 2019)

- Pintu merupakan akses utama untuk keluar dan masuk pengguna ruang. Untuk bangunan dengan fungsi khusus ICU, sebaiknya memiliki dua pintu dengan bukaan lebar sebagai akses untuk sirkulasi masuk dan keluar pengunjung secara terpisah untuk memperlancar sirkulasi pengunjung.
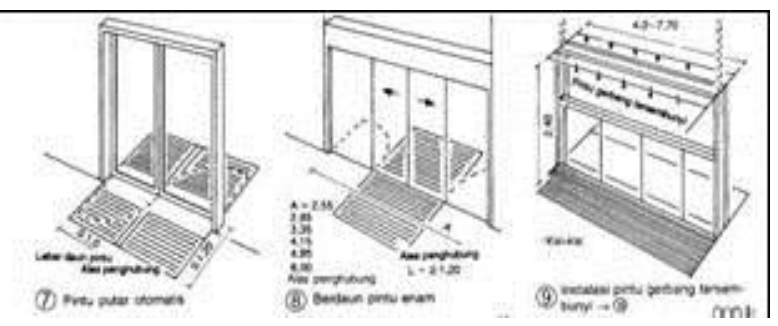

Gambar 6. Macam-macam pintu.

(Sumber: Neufert P., 2019)

- Jendela yang berkaitan dengan penghawaan merupakan salah satu faktor yang menjadi tolak ukur kenyamanan ruang. Semakin baik sirkulasi udara, semakin baik pula kualitas ruang. Pada ruang tunggu rumah sakit, pasien, pengunjung, dan karyawan berada pada satu ruang dalam waktu yang cukup lama. Semakin banyak antrian, semakin meningkat pula jumlah penggguna ruang. Akibatnya, ruang menjadi terasa penuh dan sumpek jika tidak memiliki sirkulasi udara yng baik. Pada kondisi ini, ventilasi udara menjadi sangat penting yang secara langsung berkorelasi dengan keberadaan elemen jendela pada ruang.

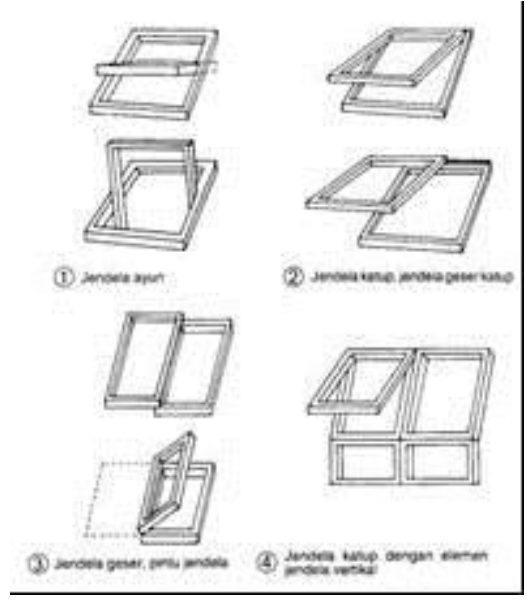

Gambar 7. Jenis-jenis jendela

(Sumber: Neufert P., 2019)

- Warna merupakan kekuatan yang dapat mempengaruhi manusia dengan menyebabkan timbulnya suatu perasaan sehat ataupun lesu. Pengaruh warna terhadap manusia terjadi secara tidak langsung, tetapi melalui pengaruh psikologis pengguna ruang itu sendiri. Warna hangat memiliki pengaruh aktif dalam merangsang kejiwaan seseorang, sedangkan warna dingin lebih bersifat pasif dan menenangkan bagi pengguna ruang. Namun perlu diperhatikan besar kecilnya pengaruh warna terhadap pengguna ruang juga didukung oleh pencahayaan pada ruang tersebut.

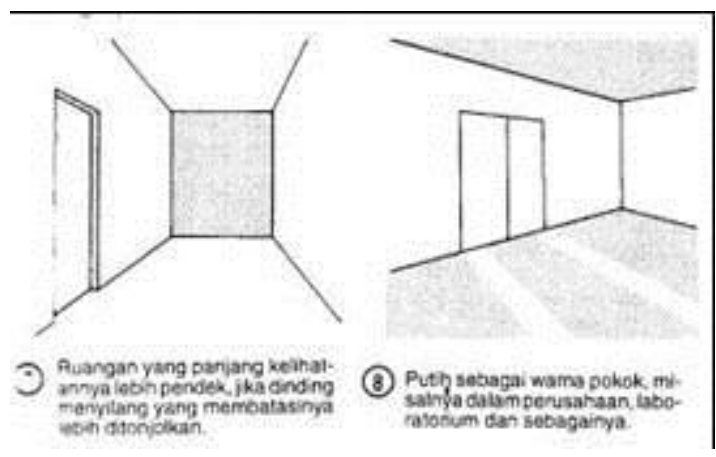

Gambar 8. Elemen warna pada ruang

(Sumber: Neufert P., 2019)

\section{TINJAUAN OBJEK PENELITIAN}

Rumah sakit umum klungkung adalah rumah sakit terbesar di wilayah Bali timur. Pelayanannya mencakup wilayah Klungkung, 
Karangasem dan juga Bangli. Pasien yang dilayani yaitu outpatient (pasien rawat jalan /poliklinik) dan inpatient (pasien rawat inap). Kegiatan medis untuk menunjang agar rumah sakit bisa beroperasi secara optimal bisa dibagi menjadi dua, yaitu (1) Kegiatan utama yang merupakan kegiatan operasional rumah sakit baik medis dan paramedis; dan (2) Kegiatan penunjang yang merupakan kegiatan administrasi /direksi rumah sakit dan rumah tangga.

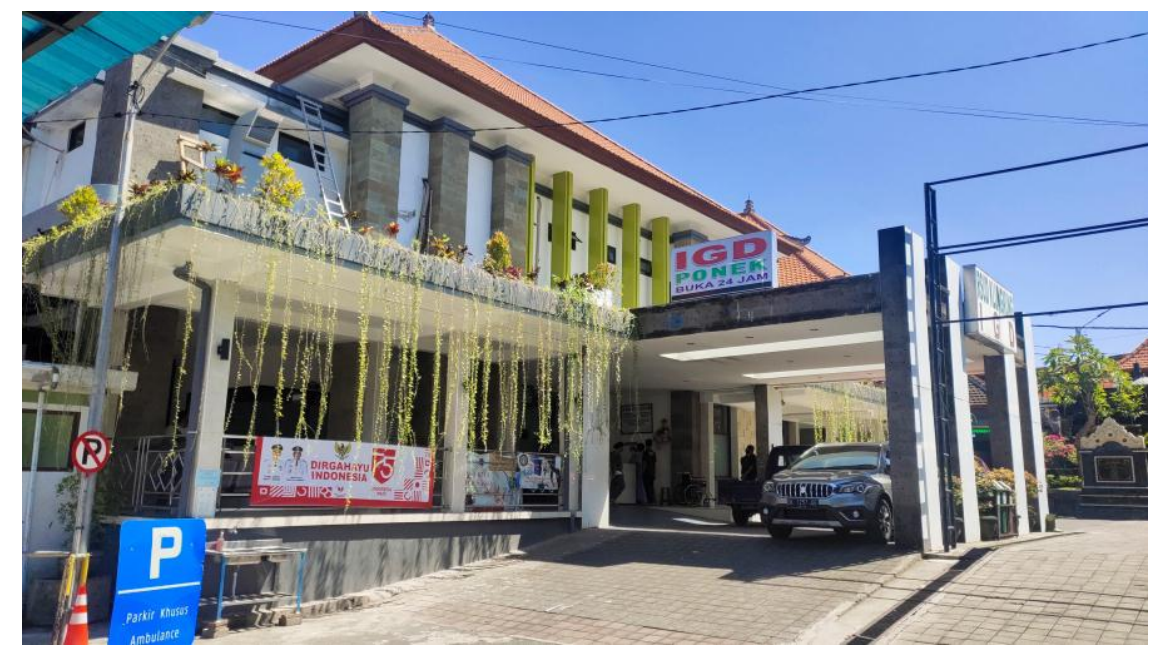

Gambar 8. Gedung IGD dan ICU RS Klungkung

(Sumber: Dokumentasi Pribadi., 2020)

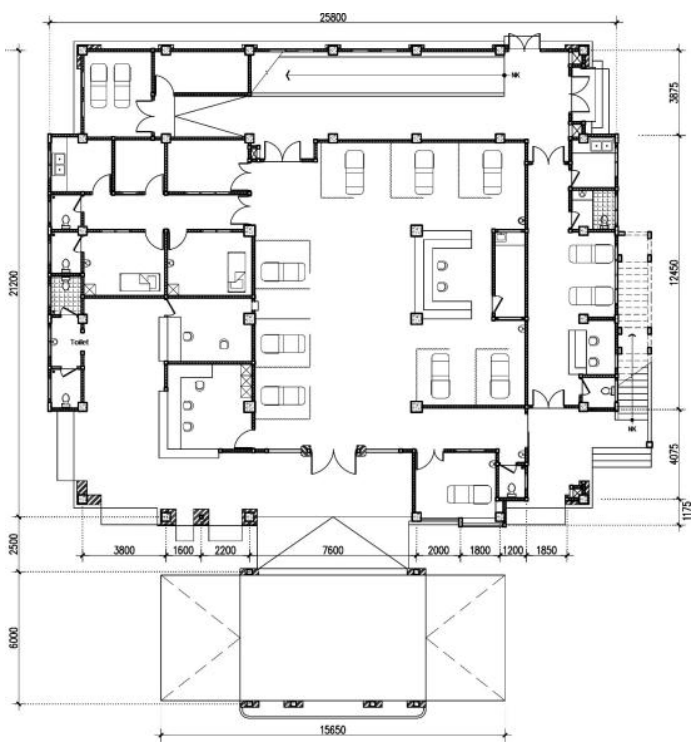

Gambar 8. Denah Lantai 1 Pelayanan IGD (Sumber:: Dokumen Perencanaan, 2015)

\section{HASIL DAN PEMBAHASAN}

\section{Kenyamanan Gerak}

Fokus pada area pelayanan ICU RS Klungkung, terdapat beberapa permasalahan terkait kapasitas dan kenyamanan pengguna

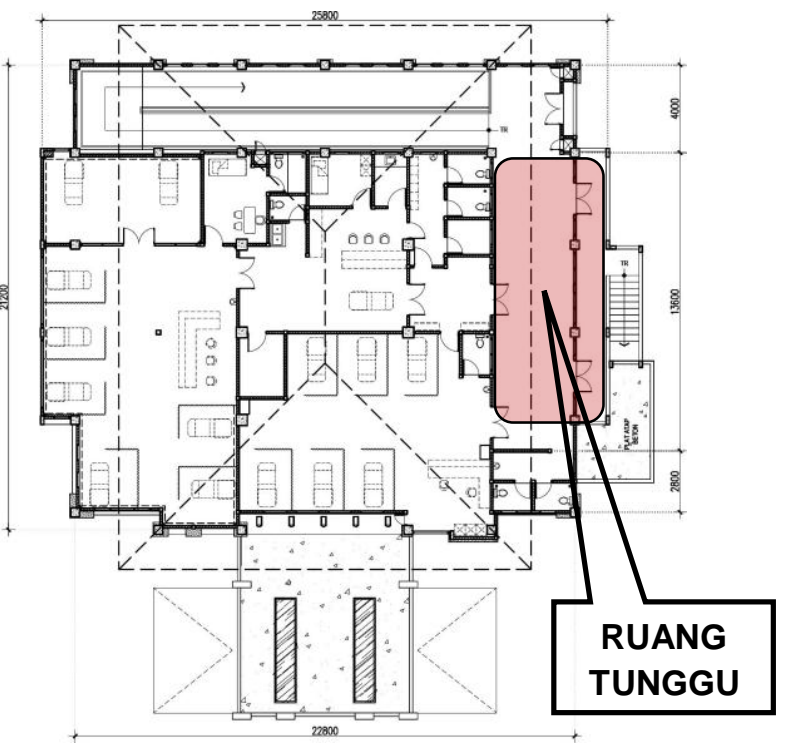

Gambar 8. Denah Lantai 2 Pelayanan ICU (Sumber: Dokumen Perencanaan, 2015)

ruang. Berdasarkan hasil observasi pada Tabel 1, dapat ditemukan beberapa aspek yang tidak memenuhi standar. Ruang tunggu diantaranya ukuran ruang, penempatan tempat duduk, dan pencahayaan alami yang masih kurang memadai. 
Tabel 1

Hasil Observasi Kenyamanan Gerak

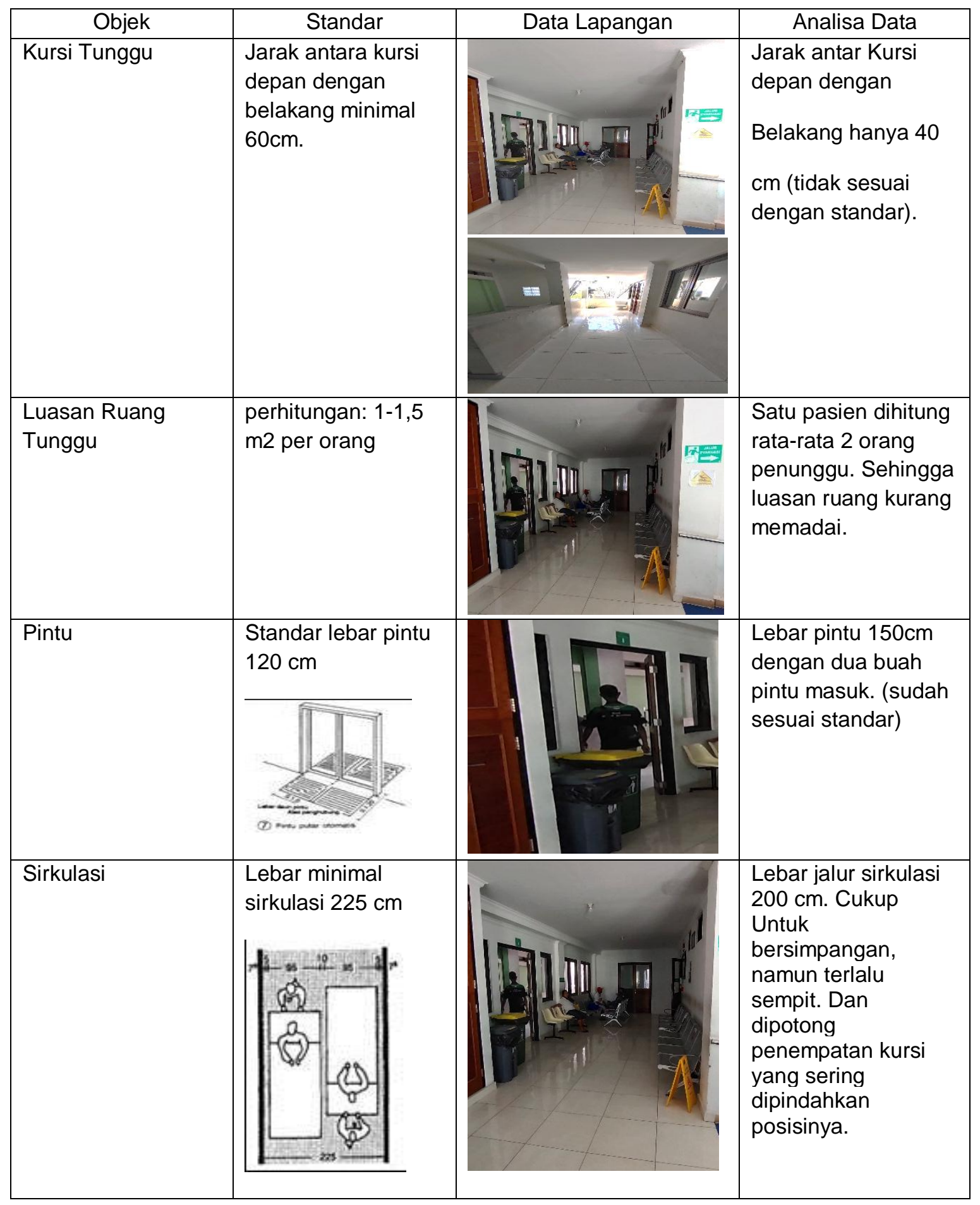

\section{Kenyamanan Visual}

Ukuran kenyamanan suatu ruang tidak hanya ditentukan oleh kenyamanan gerak saja, tetapi juga ditentukan oleh kenyamanan visual. Tabel berikut memperlihatkan hasil observasi kenyamanan visual di ruang tunggu ICU RS Klungkung. 
Tabel 2

Hasil Observasi Kenyamanan Visual

\begin{tabular}{|c|c|c|c|}
\hline Objek & Standar & Data Lapangan & Analisa Data \\
\hline Pencahayaan & & 11. & $\begin{array}{l}\text { Pencahayaan alami } \\
\text { melalui jendela di } \\
\text { samping yang } \\
\text { sudah cukup luas. } \\
\text { Tetapi di samping } \\
\text { ruang tunggu ICU } \\
\text { adalah gedung lain, } \\
\text { sehingga cahaya } \\
\text { matahari terhalang. }\end{array}$ \\
\hline Dinding & $\begin{array}{l}\text { Ornamen menarik } \\
\text { diberikan pada } \\
\text { dinding tertentu } \\
\text { agar tidak monoton } \\
\text { dan menjadi point } \\
\text { of interest. }\end{array}$ & $=$ & $\begin{array}{l}\text { Pada dinding baik } \\
\text { yang berhubungan } \\
\text { dengan sisi luar } \\
\text { ataupun dalam } \\
\text { hampir sebagian } \\
\text { besar diisi dengan } \\
\text { jendela } \\
\text { pencahayaan, }\end{array}$ \\
\hline Warna & $\begin{array}{l}\text { Warna terang } \\
\text { memberikan kesan } \\
\text { luas terhadap } \\
\text { ruang. }\end{array}$ & & $\begin{array}{l}\text { Warna putih terang } \\
\text { digunakan untuk } \\
\text { seluruh dinding dan } \\
\text { plafon. }\end{array}$ \\
\hline
\end{tabular}

\section{KESIMPULAN DAN SARAN}

Faktor-faktor yang perlu diperhatikan dalam menunjang kenyamanan pada ruang tunggu ICU adalah ukuran ruang, penataan kursi tunggu; jumlah bukaan; dan pemilihan warna cat tembok, plafon, dan lantai. Semakin baik pemenuhan faktor-faktor tersebut akan menyebabkan semakin baik kenyamanan gerak dan visual di ruang tersebut. Jumlah pasien mutlak harus menjadi pertimbangan dalam merancang ukuran dan luasan ruang karena terkait satu sama lainnya. Kekurangan space ruang tunggu bisa disiasati dengan perencanaan gedung di sebelahnya agar bisa terpadu untuk perluasan ruang tunggu ICU.

Kenyamanan gerak dan visual belum sepenuhnya bisa terpenuhi di ruang tunggu pasien ICU Rumah Sakit klungkung. Beberapa fasilitas sudah tersedia sesuai dengan standar Neufert, akan tetapi masih kurang jumlahnya, hal ini dikarenakan ukuran ruang yang kurang luas dan kapasitas pengguna yang tidak sesuai sehingga tidak bisa dilakukan penempatan fasilitas yang sesuai standar. Pada saat inilah tingkat kejenuhan sangat tinggi. Ada beberapa point di dalam ruang tunggu ini yang dapat meminimalisir kejenuhan, yaitu adanya pencahayaan alami dan sirkulasi udara alami pada sisi ruang. Sementara itu pada sisi yang lain hanya menggunakan pencahayaan buatan. Pencahayaan alami yang menjadikan ruang lebih terang dipersepsikan oleh pengunjung sebagai pembentuk kenyamanan dan dapat mengurangi kejenuhan. Oleh sebab itu perlu adanya perbaikan di ruang tunggu ICU Rumah Sakit Umum Klungkung yang meliputi kapasitas, fasilitas, sirkulasi, dan interior.

\section{DAFTAR PUSTAKA}

Juniastra I Made. 2019. Jurnal IImiah Perancangan Gedung Laboratorium 
Sebagai Bagian Terintegrasi Rumah Sakit.

Nifida Alsya Khairunnisa dkk. 2020. Jurnal IImiah Kenyamanan Visual Dan Gerak Pengunjung Di Ruang Tunggu Rumah Sakit (Studi Kasus Gedung Rawat Jalan Rs. Orthopedi Prof. Dr. R. Soeharso Surakarta).

Nazir, M. 2003. Metode Penelitian. Jakarta: Ghalia Indonesia.

Neufert, Ernst. 2000. Data Arsitek. Jakarta: Erlangga.

Neufert, Peter. 2019. Data Arsitek. Jakarta: Erlangga.
Peraturan Menteri Kesehatan (Permenkes) Republik Indonesia No. 56 Tahun 2014 Tentang Klasifikasi dan Perizinan Rumah Sakit.

Peraturan Menteri Kesehatan (Permenkes) Republik Indonesia No. 24 Tahun 2016 Tentang Persyaratan Teknis Bangunan dan Prasarana Rumah Sakit.

Peraturan Menteri Pekerjaan Umum (PermenPU) No.30/MRT/M/2006 Tentang Pedoman Teknis Fasilitas dan Aksesibilitas pada Bangunan Gedung dan Lingkungan. 